\title{
QUANTIFICAÇÃO DE MATERIAL COMBUSTÍVEL SUPERFICIAL EM REFLORESTAMENTOS DE Araucaria angustifolia (Bert.) O. Ktze.
}

\author{
Alexandre Beutling*, Antonio Carlos Batista**, Ronaldo Viana Soares***, Marcelo Diniz Vitorino**** \\ *Eng. Florestal, M.Sc., Doutorando em Eng. Florestal, UFPR - ale_jeep@floresta.ufpr.br \\ **Eng. Florestal, Dr., Depto. de Ciências Florestais da UFPR - batista@floresta.ufpr.br \\ ***Eng. Florestal, PhD., Depto. de Ciências Florestais da UFPR - rvsoares@floresta.ufpr.br \\ ****Eng. Florestal, Dr., Depto. de Engenharia Florestal da FURB - diniz@furb.br \\ Recebido para publicação: 08/08/2005 - Aceito para publicação: 08/12/2005
}

\begin{abstract}
Resumo
Quantificação de material combustivel superficial em reflorestamentos de Araucaria angustifolia (Bert.) $O$. Ktze. Este trabalho foi desenvolvido em um reflorestamento de Araucaria angustifolia (Bert.) O. Ktze., pertencente à empresa Florestal Gateados, localizada no município de Campo Belo do Sul (SC), com o objetivo principal de quantificar o material combustível existente em 5 povoamentos com diferentes idades, sendo elas, 8, 19, 24, 25 e 38 anos. Foram estabelecidas para este estudo um total de 100 parcelas, divididas proporcionalmente entre os 5 povoamentos, com uma intensidade amostral mínima de 4 parcelas por hectare e média de 20 parcelas por classe de idade. Foram determinadas, em cada parcela, a área basal, a altura média da vegetação do sub-bosque, as cargas do material combustível vivo e morto, carga total por idade e cargas por classe de diâmetro dos combustíveis florestais. A carga total foi de $20,13 \mathrm{Mg} \mathrm{ha}^{-1}$ para o povoamento de 8 anos, $10,76 \mathrm{Mg}$ ha $^{-1}$ para o de 19 anos, 15,84 Mg ha-1 para o de 24 anos, $14,81 \mathrm{Mg} h a^{-1}$ para o de 25 anos e 13,24 Mg ha $^{-1}$ para o de 38 anos. Verificou-se uma proporção aproximada de 9:1 entre as cargas dos combustíveis mortos e vivos, respectivamente, sendo "miscelânea" $(38,6 \%)$ e "grimpa" $(30,46 \%)$ as classes de maior participação na constituição da carga total.

Palavras-chave: Carga de combustível; Araucaria angustifolia; combustível florestal.
\end{abstract}

\begin{abstract}
Surface fuels quantification on Araucaria angustifolia (Bert.) O. Ktze. plantations. This research was conducted in an Araucaria angustifolia plantation owned by "Florestal Gateados" company, located in "Campo Belo do Sul" county, Santa Catarina State, Brazil. The main objectives of the study were to characterize the forest fuel accumulated in 5 stands of different class ages $(8,19,24,25$ and 38 years old). A total of 100 plots, proportionally distributed among the 5 stands were established, with a minimum sampling intensity of 4 plots per hectare, and an average of 20 plots per age class. In each plot, the basal area, the mean understory vegetation height, the live and dead fuel weights by size class were measured. Results showed that the total fuel loading measured in the 5 stands were 20.13; $10.76 ; 15.84 ; 14.81$ and $13.24 \mathrm{Mg}^{-h^{-1}}$ for the $8,19,24,25$ and 38 years old plantations, respectively. Except for the 8 year old stand, the rate between dead and live fuel loading was approximately $9: 1$. Miscellaneous $(38.6 \%)$ and "araucaria" leaves and twigs $(30.46 \%)$ were the fuel classes with higher contribution to the total fuel loading.

Keywords: Fuel loading; Araucaria angustifolia; forest fuel.
\end{abstract}

\section{INTRODUÇÃO}

Os incêndios florestais são conhecidos pelo seu alto poder de destruição, sendo responsáveis por prejuízos muitas vezes incalculáveis, principalmente quando incidem sobre plantios comerciais. Comprova-se a cada dia que a melhor forma de controlar os incêndios florestais reside nas ações de prevenção, através de planos de prevenção e combate eficientes. Entretanto, a eficiência desses planos depende da qualidade de informações relacionadas ao comportamento do fogo, que pode ser estimado mediante a caracterização do material combustível, da topografia do terreno e das condições climáticas respectivas à região. 
O material combustível é o único fator no chamado "triângulo do fogo" efetivamente sujeito a alterações antrópicas e, por isso mesmo, passível de controle. A quantificação dos combustíveis florestais está fortemente relacionada às ações de combate e queima controlada, pois são eles os responsáveis por características do comportamento do fogo como intensidade e velocidade de propagação.

De acordo com Soares (1985) e Batista (1990), combustível florestal é qualquer material orgânico, vivo ou morto, no solo ou acima dele, suscetível de participação no processo de combustão. Vélez (2000) cita que é dos combustíveis florestais que dependem, mais do que de qualquer outro fator, o início e a propagação do fogo, sendo que para estimar corretamente o comportamento de um incêndio o autor frisa a necessidade de se observar, com antecedência, as particularidades dos diversos combustíveis presentes em determinada região.

Beutling (2005) menciona que os combustíveis florestais podem ser analisados com base no seguinte diagrama:

\section{Combustiveis Florestais}

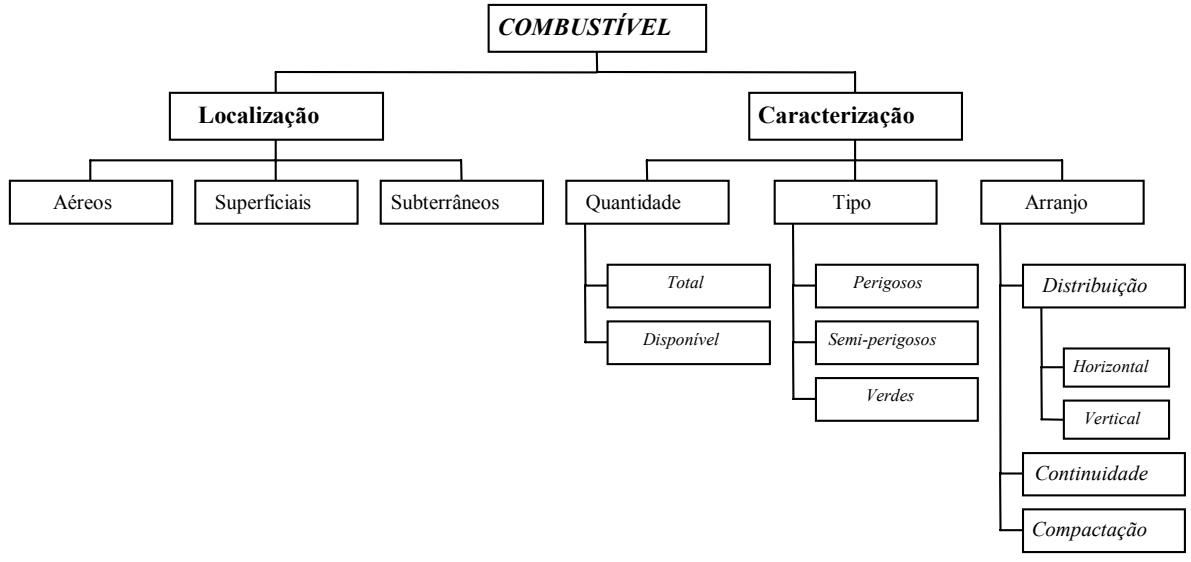

De forma geral, o material combustível apresenta uma localização no estrato florestal e é caracterizado pela quantidade, pelo tipo e pelo arranjo que possui sobre determinado local (Beutling, 2005).

Para Soares (1985), os combustíveis superficiais são todos os materiais localizados sobre e imediatamente acima ou no piso da floresta, até $1,80 \mathrm{~m}$ de altura, e compreendem basicamente folhas, galhos, troncos e demais materiais que se encontram nesse intervalo.

De acordo com Rego e Botelho (1990), a disponibilidade do material combustível para queima pode alterar-se, entre outros fatores, segundo a época do ano, o estrato florestal em que ele se encontra e a vegetação que o origina.

Dentre as espécies comerciais, os pinus e eucaliptos possuem estudos mais aprofundados sobre carga de material combustível e técnicas de prevenção e manejo do fogo. Entretanto, o mesmo não ocorre para plantios de Araucaria angustifolia. Diante desse contexto, este trabalho teve como objetivo principal quantificar o material combustível superficial existente em 5 povoamentos de araucária com diferentes idades, sendo elas $8,19,24,25$ e 38 anos.

\section{MATERIAL E MÉTODOS}

Este trabalho foi realizado em plantios de araucária de propriedade da empresa Florestal Gateados Ltda., localizados no município de Campo Belo do Sul (SC), distante $66 \mathrm{~km}$ da cidade de Lages. As áreas de estudo situam-se nas proximidades das coordenadas de $27^{\circ} 58^{\prime} 10^{\prime \prime}$ de latitude sul e $50^{\circ} 48^{\prime} 47^{\prime \prime}$ de longitude oeste (sede da empresa), com altitude variando entre 800 e 1000 metros s.n.m. De acordo com a classificação de Köppen, o clima é caracterizado predominantemente como sendo do tipo $\mathrm{Cfb}$, temperado propriamente dito, com temperatura média do mês mais frio abaixo de $18{ }^{\circ} \mathrm{C}$ (mesotérmico) com possibilidades de geada, verões frescos, com temperatura média do mês mais quente abaixo de $22{ }^{\circ} \mathrm{C}$ e sem estação seca definida (IAPAR, 2004). A vegetação predominante na região é a 
Floresta de Araucária e os Campos, conforme Klein (1978), ou Floresta Ombrófila Mista e Savanas Estépicas, segundo IBGE (1993). Os povoamentos e suas respectivas áreas foram escolhidos com base na idade e na homogeneidade do plantio, sendo que todos foram plantados com espaçamento inicial de 1,60 x 2,50 m (Tabela 1).

Tabela 1. Área de estudo.

Table 1. Study area.

\begin{tabular}{lcc}
\hline Classe de Idade & Nome do Povoamento & Área (ha) \\
\hline 8 anos & Trincheira & 2,466 \\
19 anos & Japonês I - Festuca & 4,963 \\
24 anos & Túlia II & 2,709 \\
25 anos & Túlia I & 3,418 \\
38 anos & São Judas & 2,397 \\
\hline
\end{tabular}

O trabalho foi dividido em três etapas: planejamento em escritório, execução em campo e processamento de dados em laboratório. Para o levantamento das informações de campo, foram utilizados GPS civil, computador (softwares ArcExplorer, ArcView-Gis, Excel, Word e Statgraphics 4.1), um gabarito de $1 \mathrm{~m}^{2}$ para delimitação das parcelas amostrais, um calibrador de diâmetro para classificar os materiais nas respectivas classes de diâmetro existentes, duas balanças com capacidade de 2,5 e $5,0 \mathrm{~kg}$ para pesagem do material recolhido nas parcelas, uma trena para medição da altura da vegetação de subbosque, visor de Bitterlich para estimativa da área basal do local da parcela, facão, serrote de poda, canivete, prancheta, caneta, sacos plásticos, etiquetas adesivas e duas estufas para secagem do material em laboratório.

\section{Metodologia}

Foi coletado o material combustível de 100 parcelas de $1 \mathrm{~m}^{2}$ cada, distribuídas sistematicamente sobre a área de estudo e divididas proporcionalmente entre os 5 povoamentos com uma intensidade amostral mínima de 4 parcelas por hectare e média de 20 parcelas por classe de idade. A separação dos combustíveis nas respectivas classes foi realizada com o calibrador de diâmetro. O material de cada classe foi pesado (peso da matéria úmida total) e teve uma sub-amostra retirada e submetida à secagem em laboratório $\left(75^{\circ} \mathrm{C}\right.$ durante 48 horas), para posterior determinação do peso da matéria seca total e respectiva carga da amostra na parcela. Com base nos trabalhos de Schroeder e Buck (1970), Brown e Davis (1973), Soares (1979) e Ribeiro (1997), os combustíveis florestais foram classificados de acordo com o diâmetro e estado fisiológico (material vivo ou morto) nas seguintes classes:

1. Material combustível vivo, subdividido em dois grupos:

a) material herbáceo: vegetais que tinham a consistência e o porte de erva. Ex: gramíneas e samambaias;

b) material vivo lenhoso: vegetais que tinham a natureza, aspecto ou consistência lenhosa ou de madeira, sendo que, nesse caso, essa categoria ainda foi subdividida nas seguintes subclasses: V1:

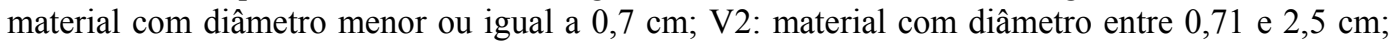
V3: material com diâmetro entre 2,51 e 7,6 cm; V4: material com diâmetro maior que 7,6 cm.

2. Material combustível morto: constituído pelo material morto acamado sobre a supefície do povoamento, de natureza, aspecto ou consistência lenhosa ou de madeira, subdividido nas seguintes subclasses: miscelânea - material fino em decomposição, de diâmetro inferior a $0,7 \mathrm{~cm}$, que formava uma massa uniforme cujos elementos já não permitiam uma identificação e classificação seguras; $\mathrm{S} 1$ material com diâmetro inferior ou igual a $0,7 \mathrm{~cm}$; S2 - material com diâmetro entre 0,71 e 2,5 cm; S3 - material com diâmetro entre 2,51 e 7,6 cm; S4 - material com diâmetro superior a 7,6 cm - estróbilo (órgão reprodutor masculino da espécie, também denominado de amentilho masculino), grimpa (conjunto de ramos secundários compostos por folhas, característicos do gênero Araucaria).

Os procedimentos de coleta de dados em cada parcela foram:

a) com a área limitada através de corte do material combustível no perímetro do gabarito (isolamento), foi feita primeiramente a medição da altura da vegetação do sub-bosque até 1,80 m;

b) todo o material vivo existente até $1,80 \mathrm{~m}$ de altura foi recolhido e dividido de acordo com a classificação mencionada. O material classificado como "herbáceo" foi pesado (peso da matéria 
úmida total) e teve selecionada uma sub-amostra ${ }^{1}$ representativa, que novamente foi pesada (peso da matéria úmida da amostra). Em seguida, esta recebia uma identificação e era acondicionada em saco plástico para transporte. O material combustível vivo lenhoso, por sua vez, era primeiramente separado nas classes de diâmetro que o compunham. As classes de diâmetro encontradas eram pesadas (peso da matéria úmida total), sendo retiradas sub-amostras representativas que também eram pesadas (peso da matéria úmida da amostra) e, posteriormente, recebiam identificação para, finalmente, serem acondicionadas em sacos plásticos para transporte;

c) o material morto superficial era separado nas classes de diâmetro encontradas e seguiam os mesmos procedimentos acima mencionados;

d) determinação da área basal com auxílio do visor de Bitterlich, realizando-se uma leitura para cada parcela estabelecida.

O trabalho realizado em laboratório foi conduzido na seguinte sequência:

a) secagem das sub-amostras do material combustível coletado nas parcelas em estufa, por um período de 48 horas, à temperatura constante de $75^{\circ} \mathrm{C}$;

b) determinação do peso de matéria seca das sub-amostras;

c) determinação do teor de umidade com base no peso da matéria seca;

d) determinação dos valores médios, para cada projeto, das seguintes variáveis: área basal e altura da vegetação do sub-bosque;

e) determinação, em cada povoamento, da carga de material combustível total, da carga de material combustível vivo, da carga de material combustível morto e da carga de material combustível por classe de diâmetro dos combustíveis florestais;

f) desenvolvimento de cálculos estatísticos. Para essa etapa, considerou-se cada idade como sendo um tratamento, de forma que os projetos ficassem identificados da seguinte maneira: Classe de idade de 8 anos - Tratamento 1; Classe de idade de 19 anos - Tratamento 2; Classe de idade de 24 anos - Tratamento 3; Classe de idade de 25 anos - Tratamento 4 e Classe de idade de 38 anos Tratamento 5. Para realização dos testes de comparação de médias, foi utilizado o Teste SNK Student, Newman e Keuls. Os dados obtidos foram analisados estatisticamente por comparação de médias, a $95 \%$ de confiabilidade.

\section{RESULTADOS E DISCUSSÃO}

A tabela 2 apresenta os dados de altura da vegetação de sub-bosque e área basal dos povoamentos estudados.

Tabela 2. Características dos povoamentos de araucária com base na idade de plantio.

Table 2. Araucaria stands characteristics according to the plantation age.

\begin{tabular}{lccccc}
\hline \multirow{2}{*}{ Dados } & \multicolumn{5}{c}{ Idade dos povoamentos (anos) } \\
\cline { 2 - 5 } & $\mathbf{8}$ & $\mathbf{1 9}$ & $\mathbf{2 4}$ & $\mathbf{2 5}$ & $\mathbf{3 8}$ \\
\hline Altura média da vegetação de sub-bosque $(\mathrm{m})$ & $1,26 \mathrm{a}$ & $0,51 \mathrm{~b}$ & $0,62 \mathrm{bc}$ & $0,70 \mathrm{c}$ & $0,65 \mathrm{bc}$ \\
Área basal $\left(\mathrm{m}^{2}\right.$.ha $\left.{ }^{-1}\right)$ & $6,80 \mathrm{a}$ & $29,76 \mathrm{~b}$ & $40,13 \mathrm{c}$ & $41,48 \mathrm{c}$ & $32,65 \mathrm{~b}$ \\
\hline Médias seguidas por letras diferentes indicam diferenças estatísticas na comparação entre os pares de valores da mesma classe \\
em relação à idade dos povoamentos.
\end{tabular}

No talhão de 8 anos, foi observada uma grande quantidade de gramíneas, que foram as responsáveis pela elevada altura e quantidade de combustível desse povoamento. Os valores de área basal, geralmente calculados levando-se em consideração todas as árvores existentes, refletem, no povoamento de 8 anos, apenas a contagem dos indivíduos de araucária, única espécie arbórea existente.

A tabela 3 apresenta os valores de carga dos combustíveis vivos, dos combustíveis mortos e a carga total, obtidas por idade do plantio nas classes encontradas do material combustível.

A carga total do povoamento de 8 anos foi formada principalmente pelos combustíveis vivos, que representaram ,em valores percentuais, aproximadamente $99 \%$ do combustível superficial amostrado

\footnotetext{
${ }^{1}$ As sub-amostras foram obtidas mediante a homogeneização do total de material obtido em cada uma das classes de material combustível e possuíam peso úmido mínimo de $100 \mathrm{~g}$.
} 
nessa idade. Também observou-se que os valores de carga dessa classe foram estatisticamente iguais nos povoamentos com idades mais avançadas, evidenciando uma possível homogeneidade quanto à carga dos combustíveis vivos em povoamentos mais velhos.

Tabela 3. Carga dos combustíveis florestais por classe de idade.

Table 3. Fuel load per age class.

\begin{tabular}{lccccc}
\hline & \multicolumn{5}{c}{ Idade dos povoamentos (anos) } \\
\cline { 2 - 6 } Classe dos combustíveis & $\mathbf{8}$ & $\mathbf{1 9}$ & $\mathbf{2 4}$ & $\mathbf{2 5}$ & $\mathbf{3 8}$ \\
\cline { 2 - 6 } & \multicolumn{4}{c}{ Carga do material combustível (base peso de matéria seca) em $\mathbf{M g ~ h a}^{-1}$} \\
\hline Total vivo & $19,91 \mathrm{a}$ & $1,06 \mathrm{~b}$ & $1,73 \mathrm{~b}$ & $2,21 \mathrm{~b}$ & $2,05 \mathrm{~b}$ \\
Total morto & $0,22 \mathrm{a}$ & $9,7 \mathrm{~b}$ & $14,11 \mathrm{c}$ & $12,6 \mathrm{~cd}$ & $11,19 \mathrm{bd}$ \\
\hline CARGA TOTAL & $20,13 \mathrm{a}$ & $10,76 \mathrm{~b}$ & $15,84 \mathrm{c}$ & $14,81 \mathrm{c}$ & $13,24 \mathrm{bc}$ \\
\hline Médias seguidas por letras diferentes indicam diferenças estatísticas na comparação entre os pares de valores da mesma classe \\
em relação à idade dos povoamentos.
\end{tabular}

Nas demais idades, os combustíveis mortos passaram a figurar como principais constituintes da carga total. Nesses povoamentos, as gramíneas (responsáveis pela elevada carga dos combustíveis vivos) não possuíam a mesma representatividade, sendo a carga dos combustíveis verdes formada principalmente por espécies de aspecto lenhoso, correspondentes às classes V1, V2 e V3 (Tabela 4). Em termos práticos, isso refletiu o estabelecimento das espécies mais adaptadas ao sombreamento, conforme o processo de sucessão natural, pois, excetuando-se o plantio de 19 anos, que sofrera desbaste de $35 \%$ das árvores em 2003, os demais povoamentos encontravam-se há vários anos sem interferência.

Apesar da composição fundamentalmente diferente, Ribeiro e Soares (1998), em um estudo sobre caracterização de material combustível superficial de um povoamento de Eucalyptus viminalis Labill. com 10 anos de idade, realizado no município de Três Barras (SC), encontraram valores médios de carga de $27 \mathrm{Mg} \mathrm{ha}^{-1}$. Batista (1995) determinou em um povoamento de Pinus taeda L. com 12 anos de idade, sem desbaste, localizado no município de Sengés (PR), carga de 12,53 $\mathrm{Mg} \mathrm{ha}^{-1}$. No município de Telêmaco Borba (PR), Valeri e Reissmann (1989), também trabalhando em povoamentos de Pinus taeda, determinaram carga de $24,3 \mathrm{Mg} \mathrm{ha}^{-1}$ para plantios com 14 anos de idade.

A tabela 4 apresenta os valores de carga obtidos por classes de diâmetro dos combustíveis vivos e mortos.

Tabela 4. Carga dos combustíveis vivos e mortos nas classes de diâmetro.

Table 4. Dead and alive fuel load per diameter and age class.

\begin{tabular}{ccccccc}
\hline \multirow{2}{*}{ Classe dos combustíveis } & \multicolumn{5}{c}{ Idade dos povoamentos (anos) } \\
\cline { 3 - 6 } & & $\mathbf{8}$ & $\mathbf{1 9}$ & $\mathbf{2 4}$ & $\mathbf{2 5}$ & $\mathbf{3 8}$ \\
\cline { 2 - 6 } & & \multicolumn{5}{c}{ Carga do material combustível (base peso seco) em $\mathbf{~ M g ~ h a ~}^{-1}$} \\
\hline \multirow{2}{*}{$\begin{array}{c}\text { Combustíveis } \\
\text { vivos }\end{array}$} & Herbáceo & $19,91 \mathrm{a}$ & $0,97 \mathrm{~b}$ & $0,61 \mathrm{~b}$ & $0,89 \mathrm{~b}$ & $0,38 \mathrm{~b}$ \\
& $\mathrm{~V} 1$ & $0,00 \mathrm{a}$ & $0,079 \mathrm{a}$ & $0,54 \mathrm{~b}$ & $0,58 \mathrm{~b}$ & $0,86 \mathrm{c}$ \\
& $\mathrm{V} 2$ & $0,00 \mathrm{a}$ & $0,016 \mathrm{a}$ & $0,44 \mathrm{ab}$ & $0,72 \mathrm{~b}$ & $0,72 \mathrm{~b}$ \\
& $\mathrm{~V} 3$ & 0,00 & 0,00 & 0,12 & 0,007 & 0,074 \\
\hline \multirow{3}{*}{ Combustíveis } & Miscelânea & $0,00 \mathrm{a}$ & $4,85 \mathrm{~b}$ & $5,74 \mathrm{~b}$ & $5,23 \mathrm{~b}$ & $4,98 \mathrm{~b}$ \\
mortos & $\mathrm{S} 1$ & $0,00 \mathrm{a}$ & $0,34 \mathrm{~b}$ & $0,66 \mathrm{c}$ & $0,54 \mathrm{c}$ & $0,91 \mathrm{~d}$ \\
& $\mathrm{~S} 2$ & $0,00 \mathrm{a}$ & $1,46 \mathrm{~b}$ & $1,56 \mathrm{~b}$ & $1,27 \mathrm{~b}$ & $0,93 \mathrm{~b}$ \\
& $\mathrm{~S} 3$ & $0,00 \mathrm{a}$ & $0,022 \mathrm{a}$ & $0,38 \mathrm{a}$ & $0,35 \mathrm{a}$ & $1,24 \mathrm{~b}$ \\
& $\mathrm{~S} 4$ & 0,00 & 0,00 & 0,00 & 0,00 & 0,019 \\
& Estróbilo & $0,00 \mathrm{a}$ & $0,00 \mathrm{a}$ & $0,013 \mathrm{a}$ & $0,025 \mathrm{a}$ & $0,058 \mathrm{~b}$ \\
& Grimpa & $0,22 \mathrm{a}$ & $2,99 \mathrm{~b}$ & $5,74 \mathrm{c}$ & $5,16 \mathrm{c}$ & $3,02 \mathrm{~b}$ \\
\hline
\end{tabular}

Médias seguidas por letras diferentes indicam diferenças estatísticas na comparação entre os pares de valores da mesma classe em relação à idade dos povoamentos.

De acordo com a tabela 4, verificou-se que o combustível do povoamento de 8 anos de idade foi composto, em sua maioria, por materiais verdes da classe "herbáceo", e observou-se que a presença da classe "grimpa" (1,07\%) nesse povoamento era resultante de práticas de manejo (poda) ocorridas em 
2002. Souza (2000) mencionou que, nos povoamentos por ele estudados, uma maior quantidade de luz incidente sobre o piso dos talhões nas idades mais jovens pode ter favorecido o desenvolvimento da vegetação herbácea, fato condizente ao observado nesta pesquisa.

Brender ${ }^{2}$ et al. (1976) citado por Souza (2000) registrou que “(...) em povoamentos de idades mais jovens a vegetação invasora constitui a maior fração deste combustível, enquanto nas idades mais avançadas, o material morto do piso florestal chega a contribuir com até $97 \%$ da carga total do combustível superficial (...)". Os dados levantados em campo demonstraram que nos povoamentos com 19, 24, 25 e 38 anos, o material morto contribuiu com, respectivamente, 90,15\%, 89,08\%, 85,08\% e $84,51 \%$ da carga total do combustível superficial. Souza (2000) acrescentou que "(...) os combustíveis com diâmetro acima de $25 \mathrm{~mm}$ não tiveram participação significativa na carga de combustível total após o fechamento do dossel". Observando as classes V3, S3 e S4 na tabela 4, para as idades de 19, 24, 25 e 38 anos, também foi verificada uma pequena participação delas neste estudo.

Em termos percentuais, as cargas de combustível verde obtidas nas idades de 19, 24, 25 e 38 anos representaram, respectivamente, 9,94\%, 10,93\%, 14,92\% e 15,47\%. Ribeiro e Soares (1998) encontraram valores de $9,41 \%$ para a classe de materiais verdes em um povoamento de Eucalyptus viminalis com 13 anos. Os mesmos autores registraram valores médios de 49,18\% para materiais finos em decomposição. Em comparação, nos plantios de araucária, a classe "miscelânea" registrou valores de $45,1 \%$ no povoamento com 19 anos, 36,25\% para o de 24 anos, 35,37\% para o de 25 anos e 37,68\% para o de 38 anos de idade.

Em valores médios, observou-se que "miscelânea", "S2" e "grimpa" participaram, respectivamente, com 38,6\%, 9,8\% e 30,46\% dos valores de carga dos combustíveis sobre os povoamentos, ou seja, juntas, respondiam por $78,86 \%$ da quantidade de material combustível superficial existente no reflorestamento de araucária. Entretanto, despertou atenção o fato de que essas classes apresentaram redução de seus valores com o avanço da idade dos povoamentos, o que contribuiu para a redução da carga total dos combustíveis florestais (Figura 1).

Observando-se os valores de carga obtidos em cada uma das classes representativas do material combustível, verificou-se que os povoamentos estudados apresentaram para a classe "grimpa", nas idades de 19, 24, 25 e 38 anos, cargas de 2,99, 5,74, 5,16 e 3,02 $\mathrm{Mg} \mathrm{ha}^{-1}$, respectivamente. Koehler (1989) obteve para povoamentos de Pinus taeda com 15 anos de idade valores de carga de acículas variando entre 4,86 a 6,64 $\mathrm{Mg} \mathrm{ha}^{-1}$.

Ribeiro (1997), trabalhando com povoamentos de Eucalyptus viminalis, encontrou para a classe C-1MD (material orgânico em decomposição, menor que $0,6 \mathrm{~cm}$ de espessura ou diâmetro, de forma não definida, que se encontra em contato com o solo mineral), valores médios de $13,23 \mathrm{Mg} \mathrm{ha}^{-1}$, um valor bastante alto quando comparado à classe "miscelânea" deste estudo, que obteve valores médios de 5,20 $\mathrm{Mg} \mathrm{ha}^{-1}$.

A figura 1 apresenta a dinâmica da carga dos combustíveis florestais em função da idade (I) nos povoamentos estudados. Nela observa-se uma clara distinção entre a carga dos combustíveis mortos $(\mathrm{Cm})$, cuja tendência foi de aumentar na medida em que o povoamento envelhece, e a carga dos combustíveis vivos $(\mathrm{Cv})$, cuja tendência foi diminuir. Essas informações tornam-se muito úteis sob o ponto de vista da prevenção dos incêndios florestais, pois conhecer a quantidade e o estado fisiológico dos combustíveis florestais existentes em campo permite a realização de estimativas sobre o risco de incêndio e o comportamento do fogo.

Observando a curva estabelecida pela carga dos combustíveis vivos e a curva estabelecida pela altura média da vegetação de sub-bosque (Figura 2), foi possível inferir que existe uma tendência semelhante entre essas duas variáveis. Isso sugere uma possibilidade de utilização dos valores de altura média da vegetação de sub-bosque para a modelagem, objetivando a predição da carga dos combustíveis florestais vivos.

\footnotetext{
${ }^{2}$ BRENDER, E. V.; McNAB, W. H.; WILLIANS, S. Fuel accumulations in Piedmont loblolly pine plantations. North Carolina: USDA Forest Service, 1976. (Research Note INT-210).

${ }^{3}$ Para o cálculo do valor médio, não foi considerada a percentagem da classe de 8 anos de idade, por ser oriunda de poda, e não da queda natural.
} 


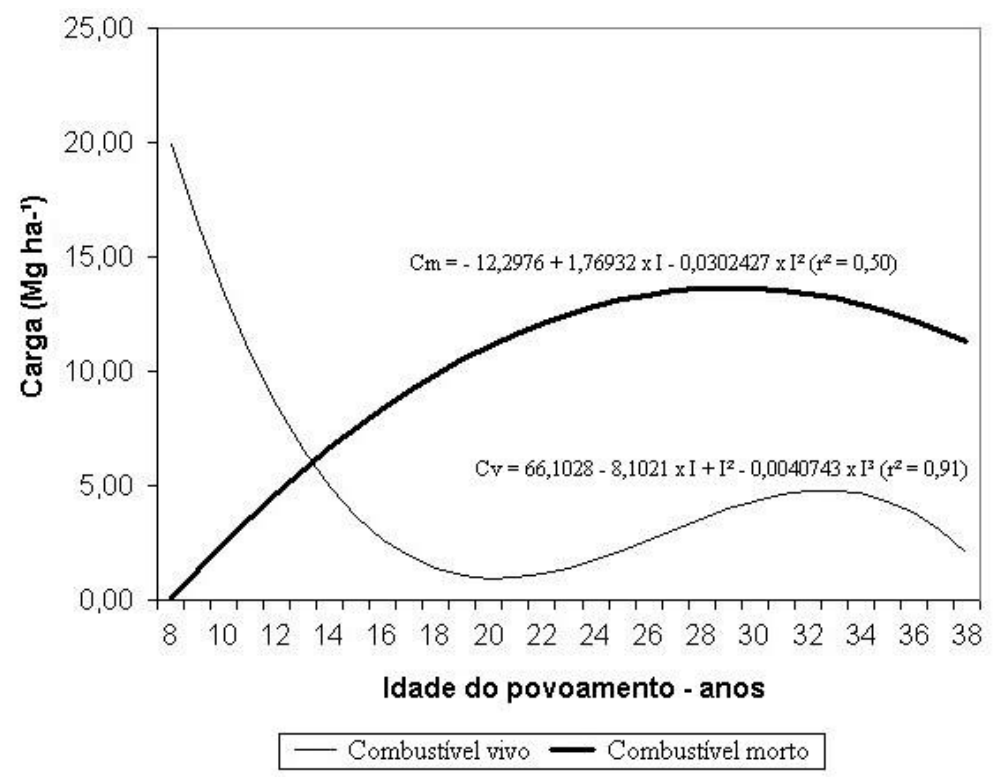

Figura 1. Dinâmica dos combustíveis florestais em função da idade do povoamento. Figure 1. Fuel load distribution according to the plantation age.

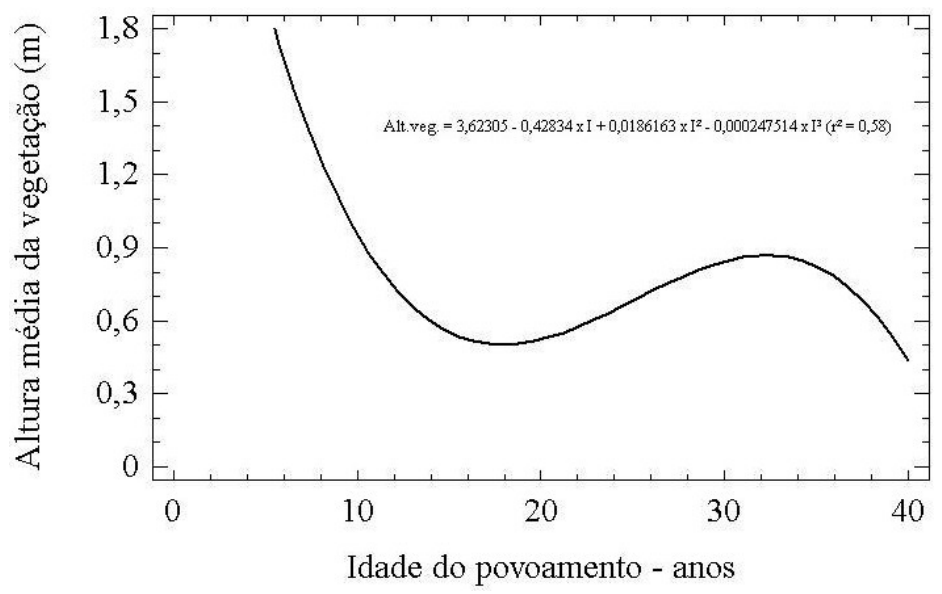

Figura 2. Altura média da vegetação do sub-bosque (m).

Figure 2. Understory medium height according to the plantation age.

\section{CONCLUSÕES}

Com base nos dados levantados pela amostragem do material combustível, concluiu-se que:

- O povoamento de 8 anos de idade apresentou a maior carga de material combustível total dentre os povoamentos estudados.

- Excetuando-se o plantio jovem (8 anos), os reflorestamentos de araucária estudados apresentaram cargas de material combustível compostas principalmente por combustíveis mortos, com uma proporção aproximada de 9:1 entre combustíveis mortos e combustíveis vivos.

- As classes de material combustível que apresentaram maior participação na constituição da carga total foram miscelânea e grimpa. 


\section{REFERÊNCIAS}

BATISTA, A. C. Avaliação da queima controlada em povoamentos de Pinus taeda L. no norte do Paraná. Curitiba, 1995. 180f. Tese (Doutorado em Engenharia Florestal) - Setor de Ciências Agrárias, Universidade Federal do Paraná.

BATISTA, A. C. Incêndios florestais. Recife: UFRPE, 1990. 115 p.

BEUTLING, A. Caracterização para modelagem de material combustível superficial em reflorestamentos de Araucaria angustifolia (Bert.) O. Ktze. Curitiba, 2005. 113 f. Dissertação (Mestrado em Engenharia Florestal) - Setor de Ciências Agrárias, Universidade Federal do Paraná.

BROWN, A. A.; DAVIS, K. P. Forest fire: control and use. 2.ed. New York: McGraw Hill Book, 1973. $686 \mathrm{p}$.

IAPAR. Cartas climáticas do Paraná. Disponível em: < http://200.201.27.90/site/sma/Cartas_Climaticas Cartas_Climaticas.htm> Acesso em: 19 nov. 2004.

IBGE. Mapa de vegetação do Brasil. Rio de Janeiro, 1993.

KLEIN, R. Mapa Fitogeográfico do Estado de Santa Catarina. Itajaí: Herbário Barbosa Rodrigues, 1978.

KOEHLER, C. W. Variação estacional da deposição de serapilheira e de nutrientes em povoamentos de Pinus taeda na região de Ponta Grossa - PR. Curitiba, 1989. 148 f. Tese (Doutorado em Engenharia Florestal) - Setor de Ciências Agrárias , Universidade Federal do Paraná.

REGO, F. C.; BOTELHO, H. S. A técnica do fogo controlado. [S.L.: s.n.], 1990.124p.

RIBEIRO, G. A.; SOARES, R. V. Caracterização do material combustível superficial e efeitos da queima controlada sobre sua redução em um povoamento de Eucalyptus viminalis. Cerne. Lavras, v. 4, n. 1, p. 58-72, 1998.

RIBEIRO, G. A. Estudo do comportamento do fogo e de alguns efeitos da queima controlada em povoamentos de Eucalyptus viminalis Labill em Três Barras, Santa Catarina. Curitiba, 1997. 145 f. Tese (Doutorado em Engenharia Florestal) - Setor de Ciências Agrárias , Universidade Federal do Paraná.

SCHROEDER, M. J.; BUCK, C. C. Fire weather: a guide for application of meteorological information to forest fire control operations. Washington, D.C., US Dep. Agric. 1970, 229 p.

SOARES, R. V. Incêndios florestais: controle e uso do fogo. Curitiba: FUPEF. 1985. 213p.

SOARES, R. V. Determinação da quantidade de material combustível acumulado em plantios de Pinus spp na região de Sacramento (MG). Revista Floresta, Curitiba, v. 10, n. 1, p. 48-62, 1979.

SOUZA, L. J. B. Modelagem de material combustível em plantações de Pinus taeda L. e Eucalyptus dunnii Maiden. Curitiba, 2000. 127 f. Tese (Doutorado em Engenharia Florestal) - Setor de Ciências Agrárias, Universidade Federal do Paraná.

VALERI, S. V.; REISSMANN, C. B. Composição da manta florestal sob povoamentos dePinus taeda L. na região de Telêmaco Borba - PR. Floresta. Curitiba, v. 19, n. 1-2, 1989.

VÉLEZ, Ricardo (Coord.). La Defensa contra Incêndios Forestales: Fundamentos y Experiencias. España. 2000. paginação irregular. 